\title{
Infant vocabulary development assessed with a British communicative development inventory
}

Article

Published Version

Hamilton, A., Plunkett, K. and Schafer, G. (2000) Infant vocabulary development assessed with a British communicative development inventory. Journal of Child Language, 27 (3). pp. 689-705. ISSN 0305-0009 doi: https://doi.org/10.1017/S0305000900004414 Available at https://centaur.reading.ac.uk/4542/

It is advisable to refer to the publisher's version if you intend to cite from the work. See Guidance on citing.

To link to this article DOI: http://dx.doi.org/10.1017/S0305000900004414

Publisher: Cambridge University Press

All outputs in CentAUR are protected by Intellectual Property Rights law, including copyright law. Copyright and IPR is retained by the creators or other copyright holders. Terms and conditions for use of this material are defined in the End User Agreement.

www.reading.ac.uk/centaur 
Central Archive at the University of Reading

Reading's research outputs online 
F. Child Lang. 27 (2000), 689-705. Printed in the United Kingdom

(C) 2000 Cambridge University Press

\title{
NOTE
}

\section{Infant vocabulary development assessed with a British communicative development inventory*}

\author{
ANTONIA HAMILTON, KIM PLUNKETT \\ University of Oxford \\ AND \\ GRAHAM SCHAFER \\ University of Reading \\ (Received I 8 Fanuary 1999. Revised 20 December 1999)
}

\begin{abstract}
Communicative Development Inventories (CDIs) were collected from 669 British children aged between $\mathrm{I} ; 0$ and 2 ; $\mathrm{I}$. Comprehension and production scores in each age group are calculated. This provides norming data for the British infant population. The influence of socioeconomic group on vocabulary scores is considered and shown not to have a significant effect. The data from British infants is compared to data from American infants (Fenson, Dale, Reznick, Bates, Thal \& Pethick, I 994). It is found that British infants have lower scores on both comprehension and production than American infants of the same age.
\end{abstract}

INTRODUCTION

There is a long tradition in the measurement of infant vocabulary (e.g. Lukens, I 894; Stern \& Stern, I 907; Benedict, I 979; Goldfield \& Reznick, I 990). Though it is obvious that a child's vocabulary increases with age, the exact course of this development and the extent of the variability between children has only recently been described. Fenson, Dale, Reznick, Bates, Thal \& Pethick ( I 994) investigated American children's comprehension and production vocabulary development between age $0 ; 8$ and $2 ; 4$, using the method of parental report. This study uses similar techniques to describe the vocabulary development norms for British children between the ages of $\mathrm{I}$; 0 and $2 ; \mathrm{I}$.

[*] We acknowledge the support of the Economic and Social Research Council, the Leverhulme Trust and the Biotechnology and Biosciences Research Council. Address for correspondence: Professor Kim Plunkett, Department of Experimental Psychology, South Parks Road, Oxford, OXI 3 UD, UK. e-mail: kim.plunkett@psy.ox.ac.uk 
Fenson et al. obtained parental reports of i 803 children's word knowledge using two versions of the MacArthur Communicative Development Inventory (CDI) - an 'infant CDI' designed for children between o; 8 and I ; 4 (the MacArthur Communicative Development Inventory: Words and Gestures), and a 'toddler CDI' for children aged between I; 4 and 2;6 (the MacArthur Communicative Development Inventory: Words and Sentences). Both of these CDIs comprised a checklist of words that a child might know, plus additional sections on actions and gestures for the infants, and sentences for the toddlers. The infant word list consisted of 396 words in 19 semantic categories. Parents ${ }^{1}$ were asked to indicate for each word if their child understood the word (but did not say it), or if their child understood AND said the word. The toddler word list was longer, with 680 words in 22 categories, but parents were only asked to indicate if their child said the word.

Fenson et al. used these data to calculate the median and Ioth, $25^{\text {th, }} 75^{\text {th }}$ and 9oth percentiles of the number of words understood by infants in consecutive monthly periods from age $0 ; 8$ to $\mathrm{I} ; 4$, and the number produced from age $0 ; 8$ to $2 ; 6$. They demonstrated that there is a wide variation in children's vocabulary scores, but that on average production vocabulary shows a rapid increase towards the end of the second year, while comprehension vocabulary increases in a more linear fashion. By using a questionnaire method they were able to study much larger numbers of children than would be practical in lab testing.

However, there have been some criticisms of the use of parental report data, notably from Tomasello \& Mervis (I994). They argue that the MacArthur CDI lacks face validity and may encourage over-inclusive responses by parents. Despite this problem, several studies suggest that parental report is a valid method of assessing infants' vocabulary.

Dale, Bates, Reznick \& Morisset ( I989) have shown that MacArthur CDI scores for infants aged I; 8 correlate closely to laboratory tests of comprehension. Bates, Bretherton \& Synder ( I 988) studied younger infants (age I ; I), and also demonstrated that comprehension of particular words in a laboratory test correlated with total comprehension score on the CDI. However, neither study directly tested whether a word marked as understood on the CDI is in the infant's receptive vocabulary.

Mills and co-workers (Mills, Coffey-Corina \& Neville, I 993, I 997) tested the validity of parental report using electro-physiological measures. Eventrelated potentials (ERPs) to auditorily-presented words were measured. They found that children's ERPs were reliably different according to whether the stimuli were known or unknown words, as rated by their parents.

These studies demonstrate the reliability of parental report in the USA.

[I] Throughout this article, the terms 'parent' and 'caregiver' are used interchangeably. 
Recently, a study in the UK has directly examined whether comprehension scores obtained using a CDI are related to infants' lexical comprehension in a laboratory setting. Schafer, Plunkett \& Thal (under review) used a preferential looking task to test comprehension of specific words at $\mathrm{I} ; 5$. Infants looked more at the image they were asked to fixate, but only if their caregiver had marked that word as 'understood' on the CDI. This suggests that British parents are reliable in their estimates of their child's receptive vocabulary on the CDI.

With colleagues, we have been using instruments similar to the MacArthur CDI for some five years, and have accumulated over $65^{\circ}$ questionnaires. These were given to the parents of children aged between I; 0 and 2; r, before the child and caregiver visited the laboratory to participate in studies using preferential looking (Golinkoff, Hirsh-Pasek, Cauley \& Gordon, I987; Schafer \& Plunkett, I 998) or preferential listening (Nelson, Jusczyk, Mandel \& Myers, i 995). Although all the CDIs used in Oxford are based on the MacArthur 'infant CDI', several different forms have been used over the years. We will refer collectively to these instruments as the 'Oxford CDI'.

In this article, we describe the vocabulary scores that we have obtained using the Oxford CDI. Our primary aim is to establish norms for vocabulary development in British infants, equivalent to those that have been described for American infants. We consider the influence of socio-economic group and the differences in the wordlist used in each version of the Oxford CDI on the vocabulary scores we obtained. Furthermore, we compare the British norms to those found in the US, and consider some reasons for the differences found between the two countries.

METHOD

Development of the Oxford CDI

CDIs have been used for developmental studies in Oxford for 4 years, mainly to assess infants' word knowledge prior to a visit to the Babylab. There have been four versions of the Oxford CDI, which differ only in the vocabulary checklist shown to parents. The instructions given to parents always remained the same, and the wordlist was divided into the following categories - animal sounds, animals, vehicles, toys, food and drink, body parts, clothes, furniture and rooms, outside, household items, people, games and routines, action words, descriptive words, question words, time, pronouns, prepositions, and quantifiers. In some versions of the CDI, an entire category was excluded, but no other structural changes were made.

The structure and word list of the Oxford CDI were originally based on the MacArthur CDI. Note that the set of items included in the MacArthur CDI was determined after an extensive evaluation of the frequency of usage of the words by children. No such evaluation was performed in the construction of the Oxford CDI. CDIs were initially used in Oxford as an aid 
to selecting materials for preferential looking studies, and made the same assumptions about frequency of word usage as the MacArthur CDI. However, we did compare some word frequency norms taken from British and American sources in order to establish whether there were any systematic discrepancies; we report on these comparisons below.

The first CDI used in Oxford was a shorter version of the MacArthur infant CDI; while the MacArthur CDI had 396 words, this pre- 1996 Oxford CDI had only 37 I words. It excluded the category 'animal sounds', some American words (e.g. diaper, trash, stroller, and cheerios) and some other words, such as the child's own name and a babysitter's name, because these were not used in our experimental studies. Two animal names (whale and zebra) were added, as were three colours. I3 I CDIs of this type were collected.

In r 996, this CDI was revised, and two new versions were used concurrently, each tailored to the requirements of a particular preferential looking study. Version A was very similar to the pre- 996 Oxford CDI, but added approximately 20 words to replace the American words that had been excluded previously (e.g. nappy, rubbish, pushchair, and cornflakes). It was used mainly with younger infants (approx. I;0). Version B had more changes, but again these were mainly exchanges of British and American words, and some extra words were added because they were needed for experimental studies. It was used mainly with older infants (approx. I; 3 to 2 ; o) Neither of these CDIs had a section on animal sounds; this section was excluded so it would be possible to add new words to the checklist without exceeding the original total of 396 words in the MacArthur vocabulary checklist. In total, 240 version A CDIs and 77 version B CDIs were collected during 1996.

In 1998, the word list used in Oxford was revised again, to create a definitive Oxford CDI; this version can be downloaded from the internet at http://epwww.psych.ox.ac.uk/babylab/BabyLabResearch.htm. These changes were intended to make the Oxford CDI as similar as possible to the American one, for overall comparison between the versions, but also to make it a general preparatory tool for experimental studies. The category of animal sounds was reinstated, and some extra words that seemed to be uncommon or arbitrary were removed (e.g. cornflakes, whale, and sitting room). A section for extra words was added, to obtain input from parents about other words their child knew, but words listed in this section were not counted in the child's vocabulary score. Some words were also listed as a pair, for example, bunny and rabbit were listed as a single item. This was intended to reduce the overall number of items on the CDI, and to ensure items were neither missed because one synonym was excluded, nor duplicated because both synonyms were listed separately. In total, the new Oxford CDI lists 433 words, but because 17 of these are pairs, the maximum vocabulary score a child can 


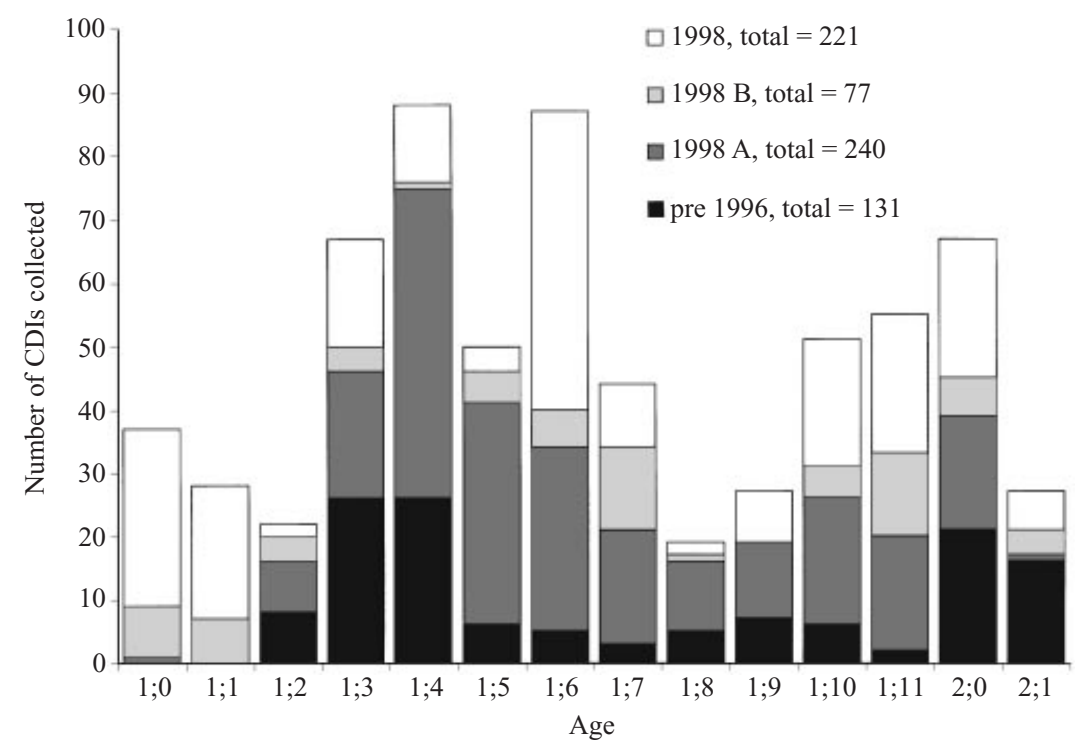

Fig. I. Number of CDIs collected in each age range for each version of the Oxford CDI.

TABLE I. The number of words that would need to be changed in each CDI wordlist to create a different version of $C D I^{a}$

\begin{tabular}{|c|c|c|c|c|c|c|}
\hline \multirow[b]{2}{*}{$\begin{array}{l}\text { CDI created } \\
\text { by changes }\end{array}$} & \multirow[b]{2}{*}{$\begin{array}{l}\text { Total number } \\
\text { of words in }\end{array}$} & & \multicolumn{4}{|c|}{ CDI to change } \\
\hline & & & MacArthur & $\begin{array}{c}\text { Oxford } \\
\text { CDI }\end{array}$ & $\begin{array}{l}\text { Oxford } \\
\text { CDI }\end{array}$ & $\begin{array}{l}\text { Oxford } \\
\text { CDI }\end{array}$ \\
\hline $\begin{array}{l}\text { MacArthur } \\
\text { Infant CDI }\end{array}$ & 396 & $\begin{array}{l}\text { Number added } \\
\text { Number removed }\end{array}$ & - & - & - & - \\
\hline $\begin{array}{l}\text { Oxford CDI } \\
\text { pre } 1996\end{array}$ & $37 \mathrm{I}$ & $\begin{array}{l}\text { Number added } \\
\text { Number removed }\end{array}$ & $\begin{array}{c}6(6) \\
3 \text { I (19) }\end{array}$ & - & - & - \\
\hline $\begin{array}{l}\text { Oxford CDI } \\
\text { I } 996, \mathrm{~A}\end{array}$ & 395 & $\begin{array}{l}\text { Number added } \\
\text { Number removed }\end{array}$ & $\begin{array}{l}27(8) \\
27(20)\end{array}$ & $\begin{array}{r}3(2) \\
28(4)\end{array}$ & - & - \\
\hline $\begin{array}{l}\text { Oxford CDI } \\
\text { I } 996, \mathrm{~B}\end{array}$ & 398 & $\begin{array}{l}\text { Number added } \\
\text { Number removed }\end{array}$ & $\begin{array}{l}4 \mathrm{I}(\mathrm{I} 8) \\
40(23)\end{array}$ & $\begin{array}{l}49(2 \mathrm{I}) \\
23(\mathrm{I} 3)\end{array}$ & $\begin{array}{l}25(\text { I } 3) \\
26(19)\end{array}$ & - \\
\hline $\begin{array}{l}\text { Oxford CDI } \\
\text { I } 998\end{array}$ & $433^{b}$ & $\begin{array}{l}\text { Number added } \\
\text { Number removed }\end{array}$ & $\begin{array}{l}6 \text { I }(36) \\
25(\text { I I })\end{array}$ & $\begin{array}{l}79(49) \\
\text { I } 8(\text { I I })\end{array}$ & $\begin{array}{l}53(46) \\
\text { I7 (10) }\end{array}$ & $\begin{array}{l}36(30) \\
\text { I (o) }\end{array}$ \\
\hline
\end{tabular}

a Numbers in brackets: the number of altered words, excluding words made into a combined entry or direct swaps of synonyms.

b 17 are pairs.

obtain is 4I 6 words. To date, $22 \mathrm{I}$ of these new Oxford CDIs have been collected.

The number of each type of CDI collected from different age groups of children is shown in Figure I. The number of words that were altered between these different versions of the CDI is summarized in Table $\mathrm{I}$, and 
the exact words used are listed in Appendix A. As the table shows, substantial changes were made to the CDI word list, both between the MacArthur and Oxford CDIs, and within different versions of the Oxford CDI. Because the length of the word list varied on different versions of the CDI, vocabulary scores were always calculated as a percentage of the maximum possible score on that CDI. However, it is possible that changes within the word list could substantially affect the vocabulary scores obtained with different versions of the CDI. A statistical comparison of the scores obtained with each version of the Oxford CDI was therefore carried out. These comparisons are described in detail in the Results section. No differences were found between the different versions of the CDI, and all the Oxford CDI data was amalgamated for all other analyses.

\section{Data collection}

In total, 669 CDIs were completed by the parents of children aged between I ; O and 2; I in the Oxford area. The majority of these were completed by caregivers in advance of a visit to the laboratory. To increase the number of subjects in under-represented age groups, extra CDIs were posted to parents on the Oxford subject panel. CDIs were excluded from the British set if the child was regularly exposed to any language other than English or had any major medical problems, but data from children with otitis media ('glue ear') was not excluded. ${ }^{2}$ For every child, total comprehension and total production vocabularies were counted and analysed.

To determine whether the infants studied in our lab represented the UK population as a whole, socio-economic data were obtained for 200 children from the Oxford subject group, by matching the child's postcode in the Manchester Census Dissemination Unit database (http://midas.ac.uk/ census/census.html). This gave each child an average socio-economic group (SEG) score based on the statistics for that child's home area. It should be noted this gives only a rough estimate of the SEG of each child's family, because data from the Census is only available as an average over groups of several postcodes. Using this data, it is possible to examine the influence of SEG on vocabulary score, and also to consider if our Oxford sample is representative of Britain as a whole.

RESULTS

Norms for British infants

$669 \mathrm{CDIs}$ were collected, and each child was given a comprehension score and production score, as a percentage of the maximum score obtainable with that CDI. The CDIs were classed in one-month age groups from I; O to 2 ; ,

[2] This was also true of the children in Fenson et al.'s study with the MacArthur CDI. 
INFANT VOCABULARY DEVELOPMENT IN THE UK

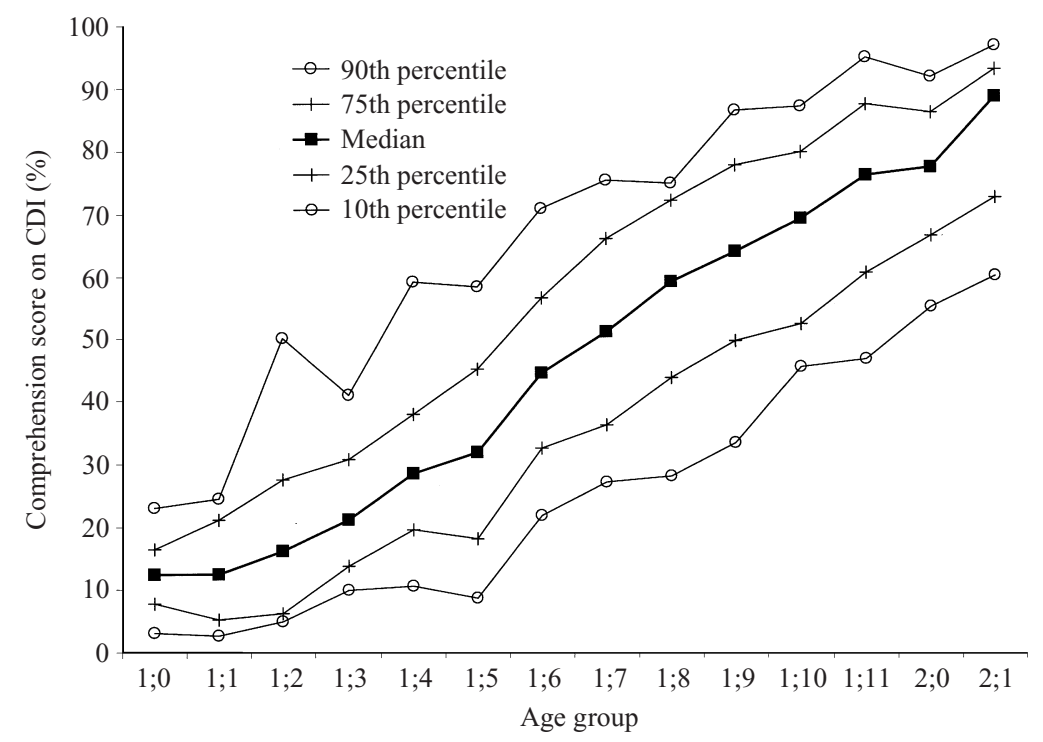

Fig. 2. Observed comprehension vocabulary in British infants.

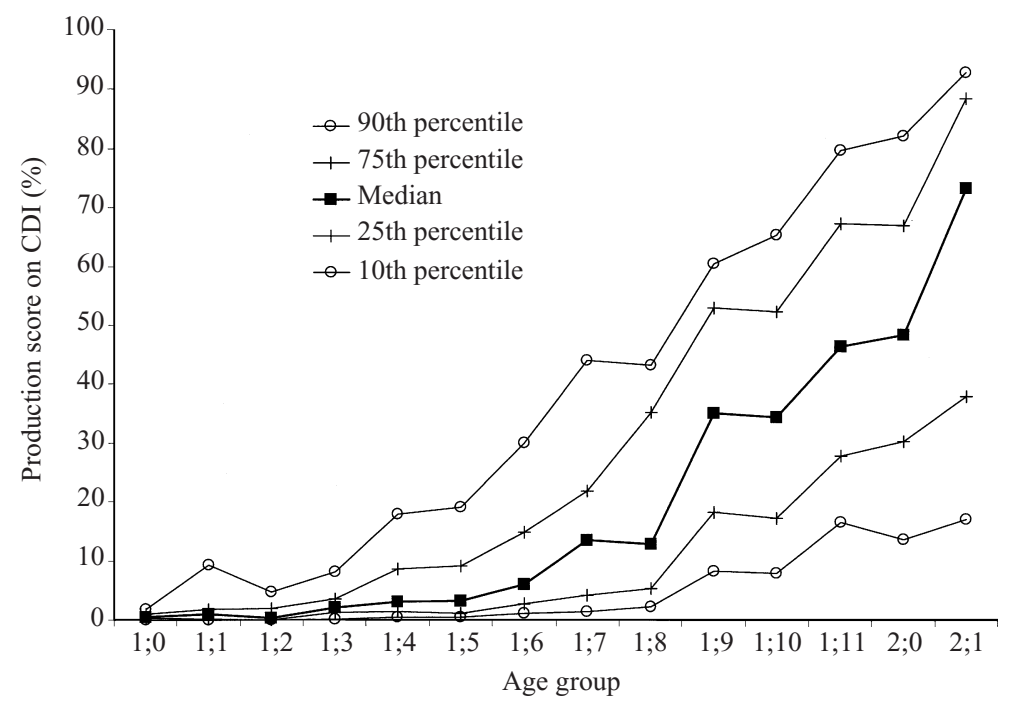

Fig. 3. Observed production vocabulary in British infants. 
and the median, Ioth, $25^{\text {th }}, 75^{\text {th }}$ and 90 th percentiles of the comprehension scores found for each age group are shown in Figure 2. The equivalent scores for production are shown in Figure 3. The data for each percentile was individually fitted to a logistic function, as advocated by Fenson et al., and the resultant curves are shown in Figure 4 and 5. These curves can be

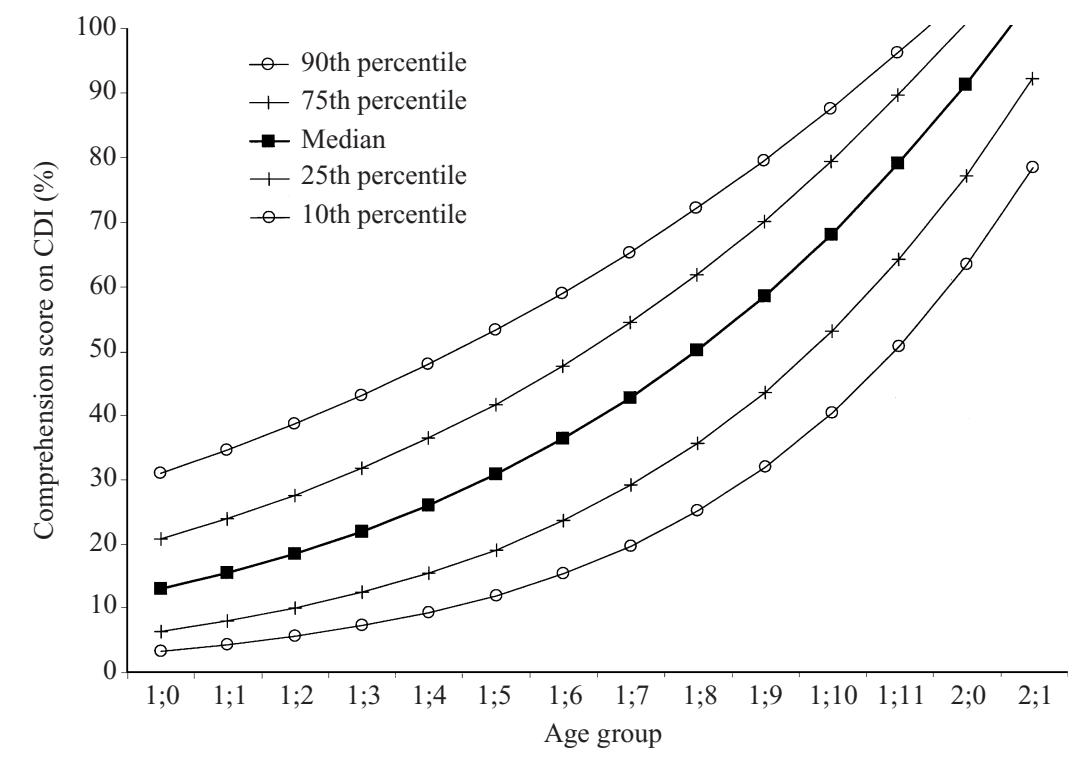

Fig. 4. Fitted comprehension vocabulary in British infants.

considered as the norms for vocabulary scores in British infants, and vocabulary data throughout this paper will be described in relation to these fitted curves.

Figure 5 illustrates that British children show an acceleration in rate of growth of expressive vocabulary during the second half of their second year, and that there is considerable variation between children. For example, children at the roth percentile master just $4 \%$ of the CDI ( 6 items ${ }^{3}$ ) at age I ; 9, and at the 9oth percentile master $50 \%$ of the CDI (200 items). Receptive vocabulary (see Figure 4) exhibits a more linear trend in development, with a limited increase in rate of growth towards the middle of the second year. As with expressive vocabulary, there is considerable variation across children. Our fitted measures of receptive vocabulary show children aged I;9 mastering $32 \%$ ( 127 items) at the roth percentile, while those at the goth percentile master $79 \%$ (3 I 9 items).

[3] Here and in future examples, the number of items is calculated assuming an average CDI wordlist of 402 items. 
INFANT VOCABULARY DEVELOPMENT IN THE UK

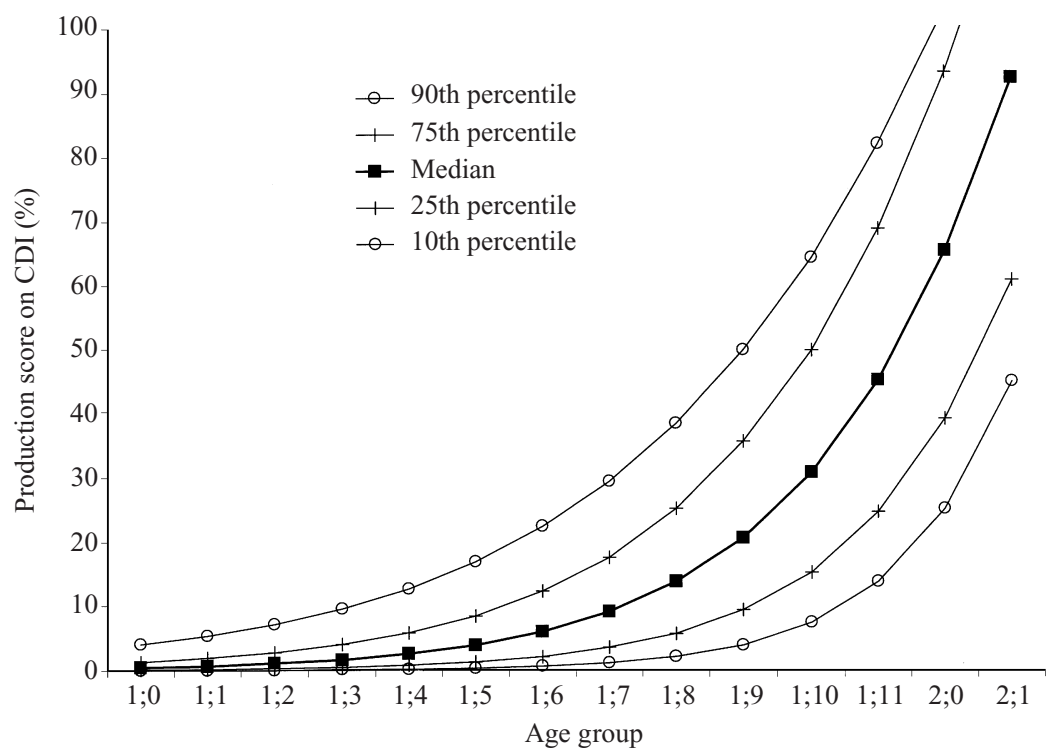

Fig. 5. Fitted production vocabulary in British infants.

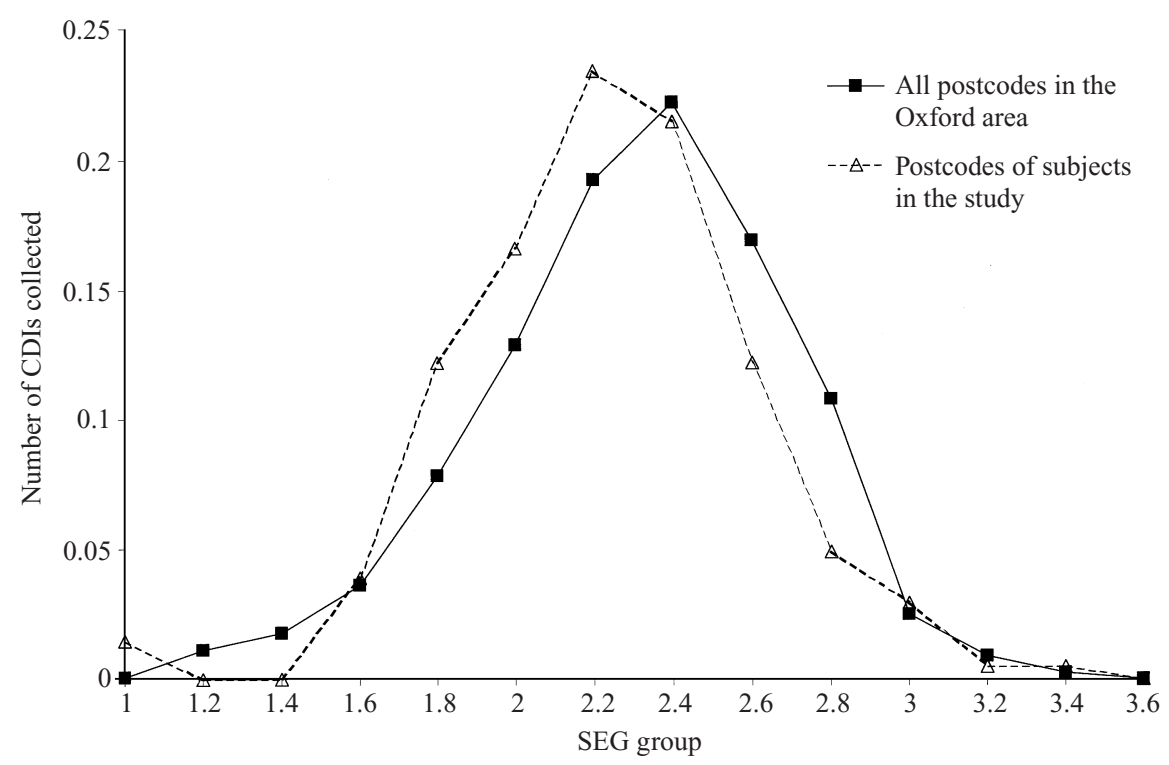

Fig. 6. Distribution of the participants in the Oxford CDI study by SEG group, compared to the overall distribution of SEG groups in the Oxford area. 
These general trends in comprehension and production vocabulary are unsurprising. They are similar in form to those that have been observed previously (Goldfield \& Reznick, I990; Fenson et al., I 994,). These studies also found considerable variation between children, and an overall linear increase in comprehension vocabulary, with some evidence for faster growth in production vocabulary.

The data relating to the SEG group of 200 infants whose parents completed CDIs was also analysed, to discover if SEG influences vocabulary score and if our sample was representative of Britain. Figure 6 shows the proportion of the children in each SEG group, and the equivalent proportions for the whole Oxford area. As the graph shows, the children in our sample are generally representative of the Oxford area, with a slight bias towards the lower end of the scale. Oxford is a fairly affluent area (the Southeast region is second in Britain in terms of disposable income per household, according to the Office of National Statistics, (http://www.statistics.gov.uk/statbase /mainmenu.asp)). It seems reasonable to assume that the majority of children in the Oxford sample were from middle class backgrounds.

A partial correlation analysis of SEG with vocabulary score, controlling for age, was carried out on the British data, and no reliable correlations were found $(r=-0.0 \mathrm{I}, p=0.8$ for comprehension and $r=0.06, p=0.4$ for production). This finding is similar to previous results (Fenson et al., I 994), and reinforces the view that SEG does not influence vocabulary score.

An investigation of the vocabulary scores obtained using different versions of the Oxford CDI was also carried out. As in previous analyses, each child's vocabulary score was expressed as a proportion of the maximum score obtainable with that version of the CDI. Figure 7 shows the average production and comprehension scores obtained in each age group for each CDI version (for subject numbers in these age groups, see Figure I).

To investigate the influence of changes in the CDI word list on children's vocabulary scores, two-way ANOVAs were performed on the Oxford comprehension and production data, (data from the MacArthur CDI could not be included in these tests, as detailed data on individual subjects were not available). The factors were age group (I4 one-month age ranges were considered as a simple factor, not a covariant, because vocabulary score does not vary linearly with age) and CDI version (four different Oxford CDIs). Both the ANOVAs showed a reliable effect of age group $\left(\mathrm{F}\left(\right.\right.$ I $\left._{3}, 6 \mathrm{I}_{7}\right)=39^{\circ}$, $p<0.00$ I for comprehension, $\mathrm{F}\left(\right.$ I $\left._{3}, 6 \mathrm{I} 7\right)=33.8,<0.00$ I for production), but neither showed a reliable effect of $\mathrm{CDI}$ version $\left(\mathrm{F}\left(3,6 \mathrm{I}_{7}\right)=0.692, p=0.56\right.$ for comprehension, $\mathrm{F}\left(3,6 \mathrm{I}_{7}\right)=\mathrm{I}_{\mathrm{I}} \cdot 87, p=0_{\mathrm{I}} 3$ for production). The results of these ANOVAs suggest that the changes of up to roo words in the CDI wordlist did not influence vocabulary scores within the British infant population studied. 


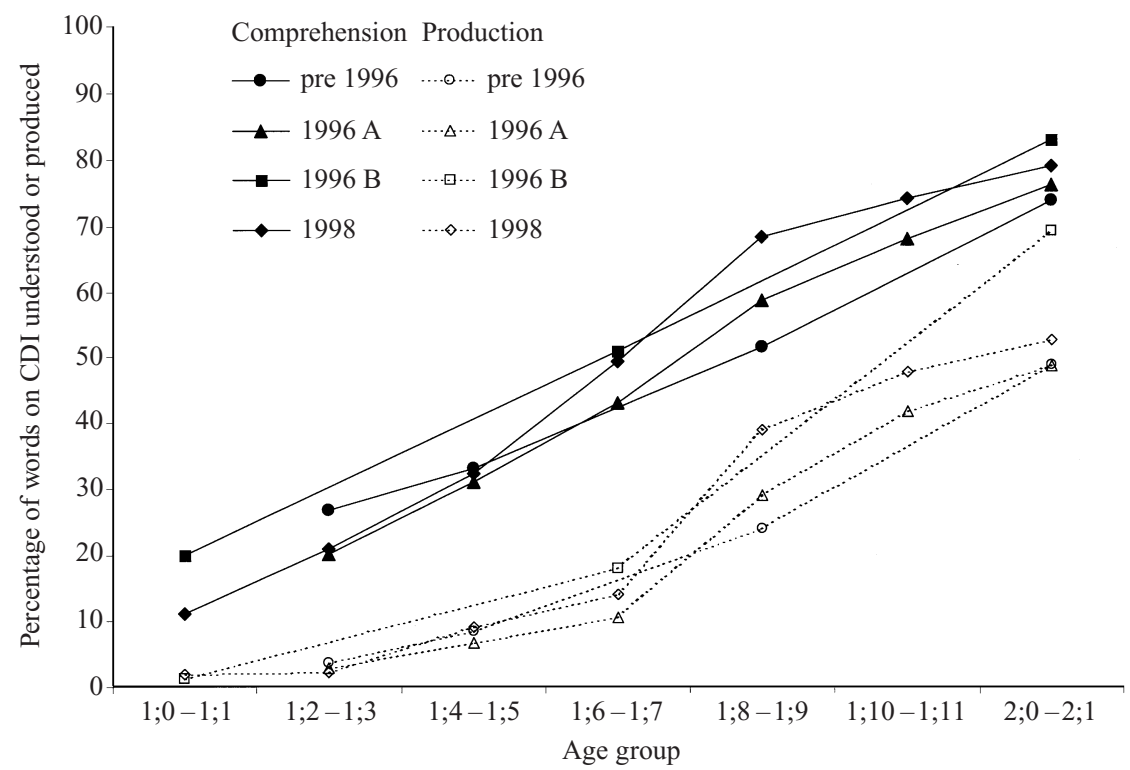

Fig. 7. Median vocabulary scores obtained using four different versions of the Oxford CDI.

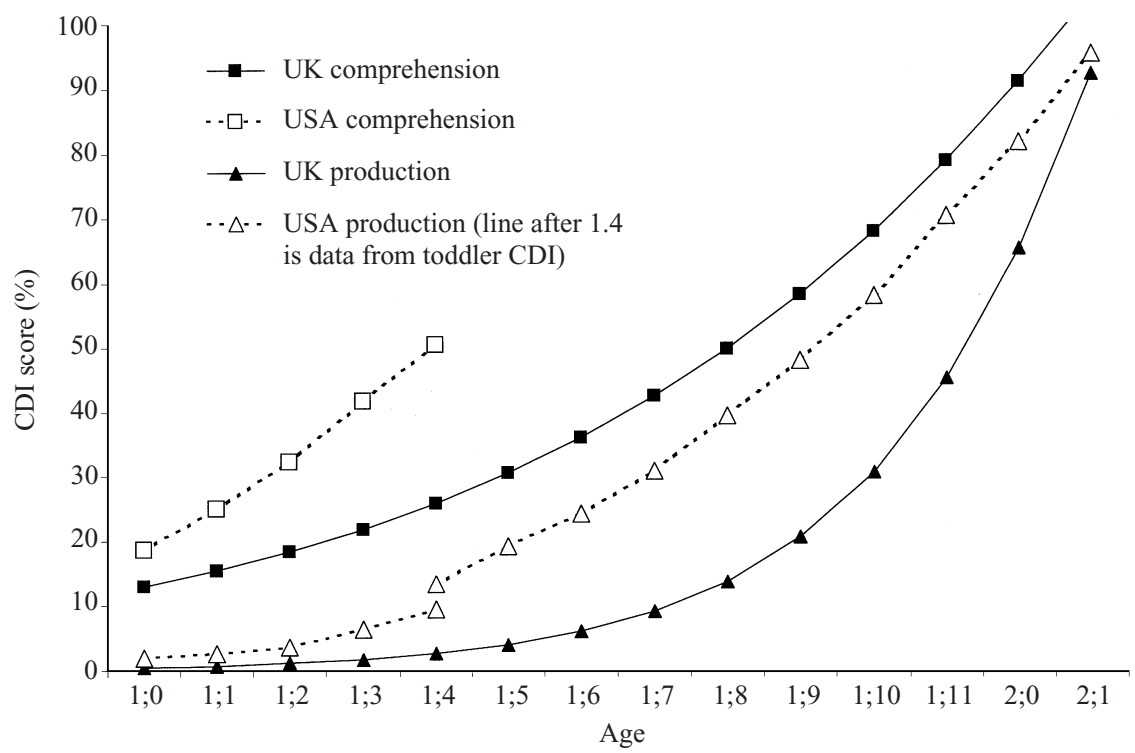

Fig. 8. Median comprehension and production vocabulary in the USA and the UK. ${ }^{a}$

${ }^{a}$ US data is redrawn from Fenson et al. (1994), Figures 2, 3 and 4. Data for the American infants production score after age $\mathrm{I} ; 4$ is derived from the MacArthur 'toddler CDI'.

699 


\section{Comparison of vocabulary scores from the UK and the USA}

The data collection instrument and analyses used in this study are similar to those used by Fenson et al., and it is interesting to compare the norms obtained from American infants with those we describe for British infants. In this study, vocabulary scores were collected from 669 infants between ages I ; O and 2; I, and were analysed as described above. Fenson et al. (1994) present data from 'infant CDIs' for 458 American children aged between o; I I and I ; 4, and 'toddler CDIs' for 886 children aged between I 4 and 2 ; ०. Exclusion criteria were similar for the studies in the UK and the US; children with major medical problems were excluded, but those with 'glue ear' were not. Bilingual children were excluded from the British data, but Fenson et al. included CDIs from children who were exposed to languages other than English, and these made up $12 \cdot 2 \%$ of their total.

The fitted median comprehension and production scores found in the USA are shown in Figure 8; the data was converted into percentage scores for comparison with the British data, which is also shown. It can be clearly seen from these figures that both production and comprehension scores are much lower for the UK sample than the US one. For example, at age I; 4, the median American infant understands approximately $50 \%$ of the words on the MacArthur CDI (200 items), while at the same age the median British infant understands only $26 \%$ of the words (ro4 items). At this age, the median production vocabulary of American infants is $9.3 \%$ (37 items), while that of British infants is $2.6 \%$ ( 10 items).

Detailed data on the vocabulary scores of individual American infants was not available, so the only way to compare the vocabulary scores from the UK and the USA statistically was to use the median vocabulary scores at each age range. A paired $t$-test on comprehension scores from age I; O to I ; 4 showed a reliable effect of country $\left(t(4)=4.3\right.$ I $_{5}, p=0.0$ I 3$)$, as did a $t$-test of production scores from I ; o to 2 ; I $(t(\mathrm{I} 3)=5.072, p<0.00 \mathrm{I})$. This confirms that there is a difference between the vocabulary scores obtained in the UK and the USA.

We also compared the frequencies of the 284 words that appeared in every version of the CDI, to identify any systematic differences in word frequency between the UK and US CDIs. Frequency data was only available for adult written word frequencies, in the Lancaster-Oslo/Bergen Corpus for British English and Brown Corpus for American English (Hofland \& Johansson, I 982). A paired $t$-test on these frequencies found a reliable difference $\left(t\left(28_{3}\right)\right.$ $=2.60, p=0.010)$, and demonstrated that the words were of a higher frequency in British English than in American English. 
DISCUSSION

We have presented vocabulary development scores for over 650 British infants aged between $\mathrm{I} ; 0$ and $2 ; \mathrm{I}$. The general trend in word learning confirms the findings of previous studies (e.g. Fenson et al., r 994), showing that there is a vocabulary spurt in production and comprehension develops in a more linear fashion. Analysis of the socio-economic group of the infants in our studies demonstrated that the majority are middle class, and are a representative sample of the Oxford area. Within this sample, there was no correlation between vocabulary development and socio-economic group.

The comparison of vocabulary scores across the four different versions of the Oxford CDI suggested that the alterations did not have any influence on the vocabulary scores obtained. This implies that the CDI is robust; the findings from it are not perturbed by common sense substitutions in the word list shown to parents.

The discovery of a large and consistent difference between vocabulary scores for infants in the UK and the USA was unexpected, and there is no clear reason for this difference. Many possible explanations could be suggested, but without more detailed data, it is only possible to speculate. Some of the explanations can be rejected outright; for example, there might be problems with the validity of parental report in either the UK or the USA, but parental report has been shown to be reliable in a number of studies from both sides of the Atlantic (e.g. Dale et al. I 989, Meints, Plunkett \& Harris, I 999, Mills et al. I 993, I 997, Schafer \& Plunkett, I 998).

The difference could be due to the changes made in the vocabulary checklists used in the UK and the USA, but the robustness of the Oxford checklist to word changes suggests that this is unlikely. Differences in word frequency between countries cannot be responsible either; we found that the 284 words present on every CDI were more common in British than American English, which would predict higher CDI scores in British infants. Differences in the subject pools are unlikely to be responsible, as both studies involved middle class children, and included children with 'glue ear', but excluded other medical conditions. Although only the American study included bilingual children, these infants would be expected to have a lower vocabulary score in English than would monolinguals (Pearson, Fernández \& Oller, I993); hence the predicted difference would be in the opposite direction to that actually observed.

There are other candidate explanations for the higher vocabulary scores in American infants. It is possible that there are subtle cultural differences between the UK and USA that influence children's vocabulary development - perhaps American parents expect their child to talk more. Different numbers of children in each study might have been in day-care; day-care children might learn words at a different rate to children at home, and their 
parents might have different knowledge of their vocabulary development (Weitzner-Lin, I996). Finally, there could be differences in referent frequency, or word frequency in infant-directed speech between the UK and the USA, which would influence the rate at which children learnt the words on the vocabulary list.

Determination of which factors are responsible for the differences in vocabulary score between British and American infants and why will require detailed investigation of cultural differences between the USA and the UK. The important point to note is that there is a large discrepancy between the vocabulary scores obtained in Britain and the USA. Researchers working with infants in the UK should be wary of using the US vocabulary development norms. Nonetheless, given previous laboratory-based validity checks on the CDI, we have good reason to continue to believe that parental report offers a valuable indication of infants' vocabulary development. To this end, we present our data as norms for the UK infant population.

\section{REFERENCES}

Bates, E., Bretherton, I. \& Snyder, L. (1988). From first words to grammar: individual differences and dissociable mechanisms. New York, C.U.P.

Benedict, H. (I979). Early lexical development: comprehension and production. Fournal of Child Language 6, i $83_{-200 .}$

Dale, P. S., Bates, E., Reznick, J. S. \& Morisset, C. (I989). The validity of a parent report instrument of child language at twenty months. Fournal of Child Language, 16, 239-5 I

Fenson, L., Dale, P. S., Reznick, J.S, Bates, E., Thal, D. J. \& Pethick, S. J. ( I 994). Variability in early communicative development. Monographs of the Society for Research in Child Development, Serial no 242, vol. 59, no 5.

Goldfield, B. A. \& Reznick, J. S. (I990). Early lexical acquisition: rate, content, and the vocabulary spurt. Fournal of Child Language $\mathbf{1 7}$, I 7 I-83.

Golinkoff, R. M., Hirsh-Pasek, K., Cauley, K. M.\& Gordon, L. (I987). The eyes have it: lexical and syntactic comprehension in a new paradigm. Fournal of Child Language $\mathbf{1 4}$, $23-45$

Hofland, K.\& Johansson, S. (1982). Word frequencies in British and American English, The Norwegian Computing Centre for the Humanities, Bergen, Norway.

Lukens, H. (i 894). Preliminary report on the learning of language. Pedagogical seminar 3, 424-60.

Meints, K. Plunkett, K. \& Harris, P. L. ( I 999). When does an ostrich become a bird: the role of prototypes in early word comprehension, Developmental Psychology 35, 1072-8

Mills, D. L., Coffey-Corina, S.\& Neville, H. J. ( I 993). Language acquisition and cerebral specialization in 20-month-old infants, Fournal of Cognitive Neuroscience 5, 3 I 7-34.

Mills, D. L., Coffey-Corina, S.\& Neville, H. J. ( I 997). Language comprehension and cerebral specialization from I 3 to 20 months. Developmental Neuropsychology 13, 397-445.

Nelson, D. G. K., Jusczyk, P. W., Mandel, D. W.\& Myers, J. (i995). The head-turn preference procedure for testing auditory perception. Infant Behaviour and Development $\mathbf{1 8}$, I I I-I I 6.

Pearson, B. Z., Fernández, S. C.\& Oller, D. K. (г993). Lexical development in bilingual infants and toddlers: comparison to monolingual norms. Language Learning 43, 93-1 20.

Schafer, G. \& Plunkett, K. (r 998). Rapid word learning by fifteen-month-olds under tightly controlled conditions. Child Development 69, 309-20

Schafer, G., Plunkett, K. \& Thal, D. J. (under review) Seventeen-month-olds do not use the contrast principle in a visual preference task. 
Stern, C. \& Stern, W. (1907). Die Kindersprache: eine psychologische und sprachtheoretische Untersuchung. (4th rev. ed.). Leipzig: Barth.

Tomasello, M. \& Mervis, C. B. (I 994). The instrument is great, but measuring comprehension is still a problem. Monographs of the Society for Research in Child Development, Serial no 242 , vol. 59 , no 5 .

Weitzner-Lin, B. (1996). Assessing communicative and linguistic development through parent and teacher report, Infant Toddler Intervention 6, 247-52.

\section{APPENDIX A}

The words which were altered in different versions of the CDI. I indicates a word was present in that version, and $\mathrm{o}$ indicates that it was absent.

PART I - WORDS THAT WERE DIRECTLY SWAPPED FOR SYNONYMS, OR FOR WHICH TWO SYNONYMS WERE COMBINED (THOUGH BOTH ARE LISTED SEPARATELY HERE)

\begin{tabular}{|c|c|c|c|c|c|}
\hline & $\begin{array}{l}\text { MacArthur } \\
\text { Infant CDI }\end{array}$ & $\begin{array}{l}\text { Oxford } \\
\text { pre '96 }\end{array}$ & $\begin{array}{c}\text { Oxford } \\
96 \mathrm{~A}\end{array}$ & $\begin{array}{c}\text { Oxford } \\
96 \mathrm{~B}\end{array}$ & $\begin{array}{c}\text { Oxford } \\
\text { I } 998\end{array}$ \\
\hline bug & I & I & o & I & o \\
\hline spider & o & 0 & I & 0 & I \\
\hline pushchair & 0 & o & I & 0 & I \\
\hline stroller & I & $\circ$ & o & 0 & o \\
\hline brick & o & o & I & I & I \\
\hline block & I & $\circ$ & I & I & I \\
\hline biscuit & o & o & I & I & I \\
\hline cookie & I & o & o & 0 & o \\
\hline candy & I & o & o & 0 & o \\
\hline sweets & o & 0 & I & I & I \\
\hline cheerios & I & ० & o & 0 & o \\
\hline cornflakes & ○ & ० & I & o & o \\
\hline diaper & I & ० & ○ & o & ○ \\
\hline nappy & 0 & o & I & I & I \\
\hline jumper & 0 & o & I & I & I \\
\hline sweater & I & I & o & I & I \\
\hline pants & I & I & ० & I & ० \\
\hline trousers & 0 & ० & I & 0 & I \\
\hline tummy button & 0 & ० & I & I & I \\
\hline belly button & I & ० & I & I & I \\
\hline settee & 0 & ० & I & I & I \\
\hline sofa & o & o & I & o & I \\
\hline $\cot$ & ० & $\circ$ & I & I & I \\
\hline crib & I & I & ० & ० & ० \\
\hline cooker & ○ & ○ & I & I & I \\
\hline stove & I & I & ० & I & ○ \\
\hline glasses & I & I & ० & I & I \\
\hline specs & 0 & $\circ$ & ० & I & I \\
\hline hoover & o & o & I & I & I \\
\hline vacuum & I & ० & I & I & I \\
\hline rubbish & ० & ० & I & I & I \\
\hline trash & I & 0 & ० & 0 & ० \\
\hline rock & I & I & $\circ$ & I & $\circ$ \\
\hline \multicolumn{6}{|c|}{703} \\
\hline
\end{tabular}


HAMILTON, PLUNKETT\& SCHAFER

\begin{tabular}{lccccc}
\hline & $\begin{array}{c}\text { MacArthur } \\
\text { Infant CDI }\end{array}$ & $\begin{array}{c}\text { Oxford } \\
\text { pre } 96\end{array}$ & $\begin{array}{c}\text { Oxford } \\
96 \mathrm{~A}\end{array}$ & $\begin{array}{c}\text { Oxford } \\
96 \mathrm{~B}\end{array}$ & $\begin{array}{c}\text { Oxford } \\
\text { I } 998\end{array}$ \\
\hline stone & $\circ$ & $\circ$ & $\mathrm{I}$ & $\mathrm{I}$ & $\mathrm{I}$ \\
shovel & $\mathrm{I}$ & $\mathrm{I}$ & $\circ$ & $\mathrm{I}$ & $\circ$ \\
spade & $\circ$ & $\circ$ & $\mathrm{I}$ & $\circ$ & $\mathrm{I}$ \\
shop & $\circ$ & $\circ$ & $\mathrm{I}$ & $\mathrm{I}$ & $\mathrm{I}$ \\
store & $\mathrm{I}$ & $\mathrm{I}$ & $\circ$ & $\mathrm{I}$ & $\circ$ \\
nasty & $\circ$ & $\circ$ & $\mathrm{I}$ & $\circ$ & $\mathrm{I}$ \\
yucky & $\mathrm{I}$ & $\circ$ & $\circ$ & $\mathrm{I}$ & $\circ$ \\
bunny & $\mathrm{I}$ & $\mathrm{I}$ & $\mathrm{I}$ & $\mathrm{I}$ & $\mathrm{I}$ \\
rabbit & $\circ$ & $\circ$ & $\mathrm{I}$ & $\mathrm{I}$ & $\mathrm{I}$ \\
kitty/kitten & $\mathrm{I}$ & $\circ$ & $\mathrm{I}$ & $\mathrm{I}$ & $\mathrm{I}$ \\
firetruck/fire engine & $\mathrm{I}$ & $\circ$ & $\mathrm{I}$ & $\mathrm{I}$ & $\mathrm{I}$ \\
motor-bike & $\circ$ & $\circ$ & $\mathrm{I}$ & $\mathrm{I}$ & $\mathrm{I}$ \\
motorcycle & $\mathrm{I}$ & $\mathrm{I}$ & $\circ$ & $\mathrm{I}$ & $\mathrm{I}$ \\
\hline
\end{tabular}

PART $2-$ SECTION CHANGES

The section on animal sounds was omitted from every CDI except the MacArthur CDI and the 1998 Oxford CDI. It contains the words - baa baa, choo choo, cockadoodledoo, grr, meow, moo, ouch, quack, uh oh, vroom, woof and yum.

I 5 verbs were added to the section Action words' in the I998 Oxford CDI, but were not present in any other CDI. They are - call, carry, catch, cuddle, cut, drop, find, have, hear, know, like, make, scratch, shut and tell.

PART 3 - MISCELLANEOUS WORDS CHANGED

\begin{tabular}{|c|c|c|c|c|c|}
\hline & $\begin{array}{l}\text { MacArthur } \\
\text { Infant CDI }\end{array}$ & $\begin{array}{l}\text { Oxford } \\
\text { pre '99 }\end{array}$ & $\begin{array}{l}\text { Oxford } \\
97 \mathrm{~A}\end{array}$ & $\begin{array}{c}\text { Oxford } \\
97 \mathrm{~B}\end{array}$ & $\begin{array}{c}\text { Oxford } \\
\text { I } 998\end{array}$ \\
\hline again & ० & $\circ$ & o & ० & I \\
\hline babysitter & I & I & ० & I & ○ \\
\hline babysitter's name & I & $\circ$ & $\circ$ & $\circ$ & ○ \\
\hline backyard & I & I & ० & ○ & ○ \\
\hline beads & I & I & o & I & $\circ$ \\
\hline bin & ○ & ० & I & $\circ$ & I \\
\hline boat & o & I & o & I & I \\
\hline bucket & ○ & ० & I & ○ & I \\
\hline cap & $\circ$ & ० & I & $\circ$ & I \\
\hline child's own name & I & $\circ$ & o & $\circ$ & ० \\
\hline chips & ० & ○ & I & ○ & I \\
\hline cracker & I & I & o & I & ० \\
\hline cute & I & I & ० & I & ○ \\
\hline doctor & ○ & ० & I & o & I \\
\hline dummy & o & o & I & o & I \\
\hline friend & ○ & o & I & o & I \\
\hline girl & I & o & I & o & I \\
\hline green & 0 & I & I & I & I \\
\hline home & I & I & 0 & 0 & $\circ$ \\
\hline \multicolumn{6}{|c|}{704} \\
\hline
\end{tabular}


INFANT VOCABULARY DEVELOPMENT IN THE UK

\begin{tabular}{lccccc}
\hline & $\begin{array}{c}\text { MacArthur } \\
\text { Infant CDI }\end{array}$ & $\begin{array}{c}\text { Oxford } \\
\text { pre '99 }\end{array}$ & $\begin{array}{c}\text { Oxford } \\
97 \text { A }\end{array}$ & $\begin{array}{c}\text { Oxford } \\
97 \text { B }\end{array}$ & $\begin{array}{c}\text { Oxford } \\
\text { I } 998\end{array}$ \\
\hline jam & $\circ$ & $\circ$ & $\mathrm{I}$ & $\circ$ & $\mathrm{I}$ \\
jug & $\circ$ & $\circ$ & $\mathrm{I}$ & $\circ$ & $\mathrm{I}$ \\
lorry & $\circ$ & $\circ$ & $\mathrm{I}$ & $\mathrm{I}$ & $\mathrm{I}$ \\
mug & $\circ$ & $\circ$ & $\mathrm{I}$ & $\circ$ & $\mathrm{I}$ \\
nail & $\circ$ & $\circ$ & $\mathrm{I}$ & $\circ$ & $\mathrm{I}$ \\
nanny & $\circ$ & $\circ$ & $\mathrm{I}$ & $\circ$ & $\mathrm{I}$ \\
noodles & $\mathrm{I}$ & $\mathrm{I}$ & $\circ$ & $\mathrm{I}$ & $\circ$ \\
owie/boo boo & $\mathrm{I}$ & $\circ$ & $\circ$ & $\circ$ & $\circ$ \\
pasta & $\circ$ & $\circ$ & $\circ$ & $\mathrm{I}$ & $\mathrm{I}$ \\
patty cake & $\mathrm{I}$ & $\circ$ & $\mathrm{I}$ & $\circ$ & $\mathrm{I}$ \\
plane & $\circ$ & $\circ$ & $\mathrm{I}$ & $\mathrm{I}$ & $\mathrm{I}$ \\
policeman & $\circ$ & $\circ$ & $\mathrm{I}$ & $\circ$ & $\mathrm{I}$ \\
raisin & $\mathrm{I}$ & $\mathrm{I}$ & $\circ$ & $\mathrm{I}$ & $\circ$ \\
rocking chair & $\mathrm{I}$ & $\circ$ & $\mathrm{I}$ & $\mathrm{I}$ & $\mathrm{I}$ \\
Tsad & $\circ$ & $\circ$ & $\circ$ & $\circ$ & $\mathrm{I}$ \\
shh & $\mathrm{I}$ & $\circ$ & $\mathrm{I}$ & $\circ$ & $\mathrm{I}$ \\
ship & $\circ$ & $\circ$ & $\mathrm{I}$ & $\circ$ & $\mathrm{I}$ \\
sitting room & $\circ$ & $\circ$ & $\circ$ & $\mathrm{I}$ & $\circ$ \\
tea & $\circ$ & $\circ$ & $\mathrm{I}$ & $\circ$ & $\mathrm{I}$ \\
wall & $\circ$ & $\circ$ & $\mathrm{I}$ & $\circ$ & $\mathrm{I}$ \\
whale & $\circ$ & $\mathrm{I}$ & $\circ$ & $\mathrm{I}$ & $\circ$ \\
white & $\circ$ & $\mathrm{I}$ & $\circ$ & $\mathrm{I}$ & $\circ$ \\
yellow & $\circ$ & $\mathrm{I}$ & $\circ$ & $\mathrm{I}$ & $\mathrm{I}$ \\
zebra & $\circ$ & $\mathrm{I}$ & $\circ$ & $\mathrm{I}$ & $\circ$ \\
\hline
\end{tabular}

